\title{
In the Service of Human Society: Formal, Informal or Anti-Logical? The Philosophy of the Logician Evert Willem Beth (1908-1964)
}

\author{
E. M. BARTH Groningen University
}

\section{Introduction}

The topic on which I have been asked to speak is, as far as I understood it, the formal-informal divide in logic. Having pondered about that task for a long time I decided that concerning a weighing of the pro's and con's of the two approaches I want to cut it short and to simply say:

There ought to be formal logic, attuned to human affairs;

There ought to be informal logic, attuned to human affairs;

and once upon a time the twain shall meet.

I do not accept the formal-informal divide as a divide. That distinction ought to be played down. It is merely a question of method-an interesting question, but not at all a threatening one. A plurality or richness of methods is something to rejoice in.

Second, I have noticed a not unsurprising lack of understanding of the origins of argumentation theory, especially in so far as these are European origins. I believe that a better understanding of those origins may contribute to a lessening of tensions caused by the formal-informal divide.

I shall try to work on your ideas by way of feeding your fantasy rather than by arguing. I'll supply you with a case history about one human being, the Dutch logicianphilosopher Evert Willem Beth, who was born in 1908 and died in 1964. His dialogically oriented philosophy happens to be one of the basic sources of argumentation theory in Europe. I shall not discuss technical details but concentrate on his outlook on logic and the needs of humanity. I do that, however, by means of a short detour.

\section{Where does European argumentation theory come from? Proof as a social act}

Where does the highly amorphous field called argumentation theory derive from? There is, I believe, a certain difference between the United States on the one hand and Europe and Canada on the other in this respect. Whereas in the United States the departments of speech communication seem to have been very influential indeed, in Europe argumentation theory derives from philosophy, and to a very large extent from logic-as in Canada.

This fact is of considerable importance for an understanding of the possibilities of, and in, the field, as I shall try to show. Five European philosophers at least from the generation before us must be mentioned, without whom this field would hardly have existed in Europe. They are, in chronological order of the onset of their work, Arne Naess of Norway, Chaim Perelman and Lucie Olbrechts-Tyteca of Belgium, Evert Willem Beth of the Netherlands, Paul Lorenzen of the German Federal Republic. One of the logicians in question, Arne Naess, has used informal methods-which made the Wiener Kreis philosophers unwilling to take his 1936 "discussion calculus" seriously. Beth and Lorenzen are formal logicians. I want to show that this last difference is less important than some hold it to be-much less important.

To start with, what these two formal logicians, Beth and Lorenzen, have done is certainly not trivial. I can prove-in an indirect manner, by means of a couple of case histories - that it is not. In 1977 the 
logician Yu. I. Manin published (an English version of) his textbook on the intimidating subject of mathematical logic, this beloved play-pen of autistic academics (my judgement, not his). The book contained one particularly remarkable section, so unusual that a couple of years later the journal The Mathematical Intelligencer published it. Manin's "provocative digression on proof", as The Mathemtical Intelligencer called it, turns out to be the following philosophical statement:

A proof only becomes a proof after the social act of "accepting it as a proof". This is as true for mathematics as it is for physics, linguistics, or biology. The evolution of commonly accepted criteria for an argument's being a proof is an almost untouched theme in the history of science. ${ }^{1}$

Then the act of "proving", too, is a social act.

This is what the editors of the journal The Mathematical Intelligencer found provocative. Manin's statement was, of course, very much in line with the spirit of the dialogical form of logic, whether formal or informal. ${ }^{2}$

In the same issue of The Mathematical Intelligencer, the editors had invited two other mathematical logicians (in the narrower sense) to participate in a discussion about this thesis and the rest of the reprinted section. One of them was Solomon Feferman from Stanford University. However, in his answer to Manin, Feferman does not discuss a single one of Manin's remarks.

\section{Logic and cultural politics}

If the Manin-Feferman verbal exchange can be called a discussion, then Feferman has lost it, for he does not deal with the thesis in question. I would like to compare this discussion (if it is one) with one that took place twenty-eight years earlier, between the Dutch logician-philosopher Evert Willem Beth ${ }^{3}$ and the American Alonzo Church, of the undecidability theorem. At that moment, in 1951, Church was editorin-chief of the Journal of Symbolic Logic (the JSL). Beth was a member of its editorial board and had been so since shortly before World War II. On 11 June 1951 Beth writes to the then editor-in-chief of the JSL, Alonzo Church, to tell him that he is very disappointed in a review that Church had sent him in manuscript for his information, of his own book Fondéments de Logique, written in French. The review, intended for the JSL, is not yet printed and Beth asks Church to request the reviewer to revise it. It is a very negative review that points out a number of technical inaccuracies and mistakes in Beth's book; and this is the only aspect of the book to which the reviewer has paid any attention at all. Beth regards this as extremely unfair, considering what he himself sees as the general aim of the book. He also (correctly) is of the opinion that a number of the mistakes or errors the reviewer refers to hardly can be characterized as errors at all. He writes:

\section{I do not question the competence of Miss Novak [the reviewer]. Nor do I fail to recognize that, to my regret, my "Fondements" contains a number of errors. I feel however-and this feeling seems to be shared by other reviewers - that these errors, most of them being minor slips, do not seriously detract from the intrinsic value of the book. Therefore I think that a review which restricts itself to listing some of these errors and adds a number of would-be mistakes, cannot do justice to my book.}

Church answers with a letter of 22 June, saying that he personally accepts the review and will publish it. He writes:

\footnotetext{
I believe that the explanation must be that your book was written hastily, under pressure of the many other obligations that I know you have undertaken, and that you simply failed to take the care and make the many detailed checks which a work of this sort demands....I do regret, when books of a low quality in matters of logic are being written, the necessity of publishing an unfavorable review of an author [Beth] of real standing in our field. But you must realize that this consideration has another
} 
side. [Certain authors of books on logic, among which is the psychologist Piaget] may deceive the outsider, but not the serious student of modern logic. The Joumal is after all addressed primarily to logicians, and it is precisely the errors of recognized logicians which it is most important to correct if our Reviews section is to perform its function (italics mine).

In his reply of June 30 , Beth starts by saying that he appreciates the frankness of Church's letter. This new letter of Beth's runs to three full typed pages. The second half of this letter is of general logicophilosophical interest. Beth now writes:

It seems to me that your outlook on the situation as a whole is entirely mistaken and that, no less than the reviewer, [you] fail to realize the fact that the book was written for French readers. Since 1940, the following books have been published in France (here five names of authors follow). I do not think that my book, in spite of a number of regrettable mistakes, is worse than any of them. Nevertheless, a French reader who consults the Journal in order to decide which book he should choose will presumably not choose mine. For this reason, the publication of the review is unjust. Now your argument is that the books [on logic] I mentioned [as not well-informed] are not by recognized logicians and therefore less harmful. But this is certainly not the opinion of prospective readers. In their opinion, the authors I mentioned are recognized specialists in logic, and this opinion will be corroborated by the review in the Journal.

In this connection I cannot help reminding you of my letter of July 29,1950 , in which I warned you against the repercussions of your policy in France.

I enclose a list of corrections to my book which I have compiled since its publication and which will be published as soon as possible.

I think it will be clear that I cannot under the present circumstances remain a consulting editor of the Journal. I therefore wish to submit to you my resignation, leaving it to you to decide at which date within the current year you prefer to drop my name from the cover... (italics mine, E. M. B.).

The letter ends on an extremely polite note.
In another letter, addressed to S. C. Kleene, Beth writes:

I am completely at a loss as to the motives behind Church's action or the lack of such motives (italics mine).

'Or the lack of such motives': this seemingly fortuitous, casual remark is in my opinion the pivot on which the Beth-Church discussion hinges. Church was not inspired by the goals and ideals that inspired Beth. Beth looked in vain for signs of the same motivation in others, suspected a gap where he himself was a sea of fire and purposeful elan, and was in this respect indeed a loner among his colleagues. As these words and the discussion in which they were uttered probably make clear Beth was-like Manin, though without publishing any explicit statement to that -inspired by a semiotical tworole philosophy which he very consistently put into practice. Thus one writes something, or proves something, for someone-and that sentence form is an irreducible form.

By means of this expression "a semiotical two-role philosophy" I hope to stimulate the readers to compare Beth's logical and semiotical philosophy (in its entirety) with certain other trends of thought in and concerning logic, first with the philosophy of the Dutch solipsist mathematician L. E. J. Brouwer (in its entirety), and then with the philosophies of more pragmatical authors such as the logicians Paul Lorenzen, Arne Naess, or Leo Apostel, or with that of Richard Rorty.

Summing up: Church is seen to use expressions such as

a work of this sort
our field
the outsider
the serious student of logic.

Not very shocking, but the difference with Beth's less usual language is impressive. In Beth's letters we find the expressions:

the book was written for ... readers the opinions of prospective readers 
the lack of such motives

a powerful expedient for rational critique philosophical and political systems

a great lack of command of logic, even in intellectual circles critical thinking (notably about philosophical and political systems) the indispensable ingredient called teaching methods

\section{Logic as rational critique: A culturally relevant discipline with empirical and pragmatical components}

Evert Willem Beth was and is the undisputed star of post-war work in philosophical as well as mathematical logic in the Netherlands. Among professional logicians Beth's methods and results in mathematical logic are famous. His work in the logical history of ideas is less well known-some of it has fortunately leaked out of the country, though it has by far not made the impact it deserves. But his general vision of the incorporation of logical problems and logical investigations into the general cultural activity was so unusual that neither the Dutch nor the international society of professional logicians could $a b$ sorb it. Beth's view on logic and its function in society is clearly based on a tworole semiotics-see above. It can perhaps be characterized as follows:

[1] He realized that theories concerning logic, old and new, to a considerable degree reflect forms of cognition which are decisive for human thought, also outside mathematics. And he assumed that a worldwide improvement of (theoretical and) practical logic is one necessary condition for the long-term improvement of human thinking. Empirical logical-cognitive research, be it of an historical or a psychological or a linguistic character, will disclose the differences and the weaknesses of contemporary modes of practical and theoretical thought. We may quite safely say that he envisaged a "cognitive science' avant la let- tre; and that he wanted the results to be used to improve human thinking in general. I shall call this the empirical component of his philosophy of logic.

[2] He regarded the improvement of human thinking as one necessary condition for the improvement of the human worldof human relations, and of human activities, verbal and non-verbal. This I shall call the pragmatical component of Beth's philosophy of logic. We could also call it the culture-oriented component. It is especially this component which distinguishes Beth from the intuitionist mathematician L. E. J. Brouwer."

[3] He assumed that 'the new logic' (socalled mathematical logic, provided that expression is taken in its widest sense), were it to become generally known and used, would mean an important step forward in structuring human thinking:

\section{Logic now does not only serve the construc- tion and investigation of mathematical and other deductive theories, it is moreover also a powerful expedient for rational critique. The creation and continuation of all kinds of philosophical and political systems is only possible owing to a great lack of command of logic, even in intellectual circles. ${ }^{5}$}

Beth here declares himself as not being an adherent of philosophical rationalism. He clearly was a staunch believer in both the practical and the theoretical value of the intellect, in daily life no less than in the sciences. However, he did not adhere to the basic value of rationalism, which is the idea that to be engaged in abstract logic and mathematics is 'the highest' cultural value and therefore the only professional "end in itself' for mathematicians and for logicians as well. His many and varied activities and his many and varied publications in fact demonstrate an uncommon system of values-uncommon among logicians. ${ }^{6}$

Now for the empirical component of Beth's philosophy. Beth wrote a number of books and articles on the history of mathematics and of logic. ${ }^{7}$ Many of these are of the encyclopedic type and reflect his 
educational zest. More important than these surveys is his own research into hidden logical patterns and (sometimes) doctrines and of how they have functioned in Western intellectual history. We shall return to this in Section 6 below.

In order to bring about an improvement in the direction of a science of logic with empirical and cultural bearings as Beth hoped for, it is necessary, I believe, that we learn to see logics as institutions. Precisely this approach is recommended in a recent book by the American philosopher John L. Pollock. "For philosophical purposes', Pollock writes, 'the institution can be identified with the set of its constitutive rules' (p. 211). In the case of logics the constitutive rules comprise at least the set of rules distributing rights and obligations over the players, or, better, over the logical roles. One may want to add also the ends for which a certain linguistic company (culture) seems to have involved certain argumentative uses of language, in as much as those uses of language - rules and obligations of the players in debates-can be seen to implement these ends. Pollock writes:

The conception of institutions which emerges from these examples is that they are essentially moral and legal instruments of a certain sort, and participation consists of the performance of acts whereby one acquires certain kinds of moral and legal obligations with respect to the institution (p. 223).

When applied to $\operatorname{logic}(\mathrm{s})$, this is exactly the insight that is needed for the purpose of constructing a technical normative logic which can be used clinically as well as constructively-as intended by Beth.

\section{The relation of Beth's work to the logic of dialogue and dialogical formal logic}

A letter from Lorenzen to Beth, written 17 August 1959, offers a particularly poignant though indirect demonstration of that two-role semiotics upon which Beth's own philosophy is based. In this letter
Lorenzen equates his own method of dialogical tableaus with Beth's semantical tableaus. This is his letter, translated into English:

Sehr verehrter, lieber Herr Beth,

Perhaps this letter will reach you before your departure to Warsaw. I am looking forward to meeting you there-for I have just received your new great book [The Foundations of Mathematics] and have started reading it, in great excitement.

It is so rich in content that I have of course so far only been able to read some of it, but I should like already now and without reservation to congratulate you with it-with the mathematical elegance with which you prove all important questions as well as for the light that you throw upon philosophical-historical connections.

Your new auxiliary, the semantical tableaus, are now very nicely and clearly exposed. I am particularly interested in these tableaus for another reason, too-and it would be extremely pleasant if we could have a close talk about it together in Warsaw. In my attempts at defining the expression definite, as I have used it in my Einfuhrung in die operative Logik und Mathematik, I have investigated how the logical constants are applied when they occur in a dialogue (between a Proponent, $\mathrm{P}$, and an Opponent, $O)$. When this dialogical usage of the logical constants is defined (in a rather obvious manner) and the ensuing dialogues written down, then $I$ arrive precisely at your tableaus (with minor differences).

May I briefly demonstrate this in connection with your example "festino"?

-asks Lorenzen, and sets to work. ${ }^{9}$

\section{The theoretical side of the pragmatical component of Beth's thought: his work as an organizer of the world of logic}

This belongs so to speak to the theoretical side of the pragmatical component in Beth's thinking. That pragmatical component also had a practical side to it. Beth put a remarkable amount of energy and time into the construction or reconstruction of national and international associations for logic and the philosophy of science. Mr. P. 
van Ulsen who has set up the Beth archives in Amsterdam writes:

Beth wanted to have a special organization for the philosophy of science and logic, independent from the ICHS, the International Council of Humanistic Science (in which one would have to deal with philosophers in general, who might very well want to participate in decision making on topics they could not possibly understand). Neither did he want it to become a sub-department of the IMU, the International Mathematical Union; for he feared that the mathematicians might drop the logicians and the philosophers of science, as a consequence of their lack of affinity to these fields. ${ }^{10}$

\section{The foundations of factual systems of thought: "Knowledge representation" and empirical logic 11}

Bordering on mathematical activities on the one side and on historico-philosophical activities on the other there is a field of research that has as yet attracted but few practitioners. Beth was the first Dutch logician to work in this field, but he had a number of well-known predecessorsBertrand Russell, Leonard Nelson, and others. Still other names are Magdalena Aebi, Arthur Prior, Jaakko Hintikka, the present author, and Philip Kitcher. This is the investigation of the various logical and semantical assumptions and paradigms that dominate or that have dominated human minds, in fact rather than ideally, and which therefore determine in no small degree the scientific as well as the political systems wrought by man. These assumptions can be, but need not have been, openly formulated as the doctrines of some normative logic; sometimes they are.

Beth came to this task well prepared, having already undertaken numerous investigations into the history of mathematics and the history of philosophy, and into the history of logic in particular. After his doctoral thesis, Rede en aanschouwing in de wiskunde (Reason and Intuition in
Mathematics, 1935) came a number of books that discussed the philosophy of mathematics from a systematic point of view, as well as books on the philosophy and the history of mathematics (1944), the history of logic $(1942,1944)$, on symbolic logic itself $(1950)$, and on the philosophy of space (1959). In 1942 he published an unorthodox analysis of Kant's classification of judgements into analytical and synthetical (cf. Beth 1953).

Whereas some of his papers may be classified as a contribution to the history of theoretical semantics, other ones are better characterized as belonging to the history of concealed but extremely influential assumptions with a logical impact. This latter field is the intersection of what is now called knowledge representation and empirical logic. In Beth's work one finds three such themes: (1) his analysis of the history, philosophy and systematical surroundings of the so-called method of exposition concerning Aristotelian syllogistics; (2) of the Platonic-Aristotelian cognitive Principle of the Absolute; (3) of the Postulate of SelfEvidence ("het evidentiepostulaat").

For reasons of time and space I shall not here have the opportunity to discuss the methodological problems and the results of this type of analysis.

Beth did not restrict his philosophical and dialogical perspective to Western thought ${ }^{12}$ (not to mention the possibility of restricting it to Europe):

For a philosophical study of logic ... a further knowledge of the logic of non-Western cultures can be of importance, Beth wrote in $1960 \ldots$... In the first place we shall have to pay attention to the availability of equivalents of our current means of expression for negation, implication (if ... then), generalization, and the modalities, and of semantical concepts such as true and false. In addition one has to count with the possibility that in connection with formal reasoning, and perhaps also in descriptions of formal reasoning, an appeal is made to other logical and semantical concepts than those that are current here and now. ${ }^{13}$ 
Given his cultural ideals and philosophical values, Beth may be said to have made a serious strategic mistake in putting those pages together with more than five hundred pages on the foundations of mathematics (as that field appeared to him in 1959), in one huge volume with this forbidding title, rather than publishing these eighty or so pages separately under another name so that it would seem accessible to the general philosopher. The title, Foundations of Mathematics, seems to keep every philosopher who is not highly skilled in abstract mathematics away from those eighty pages as well, to the serious detriment of the now budding field of "knowledge representation".

\section{Differing motives behind preoccupation with logic; Beth on critical thinking}

On this topic Beth writes, in the introduction to his Aspects of Modern Logic:

In the practice of formal logic there have always been three guiding motives:

- interest for the problems of logic as such, - the clarification of the inner relationship of certain deductive disciplines (usually mathematical theories),

- and the need for a directive for critical thinking (notably about philosophical and political systems).

In the last decades formal logic has also turned out to be important for the theory of digital computers; otherwise the emphasis, however, falls on the first two motives, which is, alas, detrimental to the application of formal logic as a guide for critical thinking. This [unfortunate fact] is related to the bonds of modern formal logic, abstract mathematics and mathematical functional studies, and to the specialistic character which symbolic logic has consequently more and more obtained. ${ }^{14}$

As to clarity this leaves nothing to be desired. Notice the objectives he himself attributes to "critical thinking": he mentions philosophical systems and political systems as well.
After Beth's death the outlook that logic also has a task as a guide for critical thinking is as a rule (there are exceptions) not taken seriously by Dutch logicians, no more than by logicians in other countries. ${ }^{15}$ Academic fashion and philosophical rationalism prevails above common sense, in the Netherlands as everywhere. Beth, however, wrote:

\footnotetext{
Now, by this development, formal logic has not in the least lost its suitability for critical thinking; the contrary is true. However, in the way of exposition of formal logic common at present, the subjects which would deserve attention with respect to this objective come to lie far apart. Therefore one cannot get to know these subjects without immersing oneself in all kinds of problems which are exclusively important for those who study logic for its own sake, or for the sake of mathematical foundational studies.
}

This means, Beth thinks, that we are confronted with the problem of restructuring the teaching of logic in such a way that logic-formal logic-can fulfill this extremely important cultural task of serving as a directive for critical thinking:

In my opinion, this is mostly to be blamed
on a lack of the indispensalbe ingredient call-
ed teaching methods. Take the numerous in-
troductory books which have appeared in the
last years. With all their good intentions,
none of the them succeed in imparting to the
reader what he really needs... ${ }^{16}$

I shall not delve into Beth's own suggestions for the teaching of logic here. It seems more important to emphasize that formal logic still does not fulfill the educational functions Beth considered it to potentially have. It looks as if in this world no more than two ideals, or two attitudes, inform the minds of the majority of professional logicians - a semi-religious belief in Reason as the one and only Ultimate Value, and in professional logicians or mathematicians as its blessed prophets; or else, unadulterated careerism. A combination of the two is not infrequent.

Beth was exceptional in this respect. $\mathrm{He}$ 
took an enormous personal joy in mathematical theories and new theses, and he had a clear ambition and desire for recognition. But in addition to this he had other ideals as well, and he fought for them in all directions, never claiming any one aspect of human logic to be the absolute and exclusive one, never condescending toward any field of human logic, provided it made some distinction between good and bad rules of reason or argument. ${ }^{17}$

Precisely what moved Beth? What spurred him on? It is difficult to put oneself into anyone else's mental position, and it is dangerous to think that one can. And yet I will try.

Beth was - and remained throughout his whole life-extraordinarily preoccupied with the terrors of World War II and its cultural roots, the rise and effects of fascism and other totalitarian modes of thought. $\mathrm{He}$ did not, as is usual, relegate his reactions to them to a secluded part of his brain that was closed off from his professional work, or vice-versa. Though the mind of no human being whosoever may form a really homogeneous unit, Beth's mind may be said to have been so to a degree that was completely unusual among his professional colleagues all over the world.

Concerning the formal-informal divide Beth wrote, in 1961 :

Formal and informal logic, the formalized languages, and the specialized technical languages of human communication do not appear simply as separate and independent occupations: they complete each other and influence one another ${ }^{18}$

It is fascinating, though saddening, to watch how people who personally have an entirely negative or zero relation with (modern) logic again and again unite academically with those logicians and mathematicians who wish to restrict the very definition of logic to algebraic methods and the foundations of mathematics, which they then serve up to the students in other departments in diluted form. ${ }^{19}$ With the blessing and encouragement of the logic-haters.

\section{Notes}

1 The Mathematical Intelligencer, vol. 2, no. 1. See also: Yu. I. Manin, A Course of Mathematical Logic, Springer-Verlag, 1977. (Empirical logic as a logical discipline is intended to take up, among other things, precisely this development of criteria for the goodness or badness of arguments-though not as restricted to mathematics).

2 Manin goes on to speak about "levels of proofness" , saying that "Every proof that is written must be approved and accepted by other mathematicians, sometimes by several generations of mathematicians' (1.c.). Cf. E. C. W. Krabbe's "levels of strictness" in modal logic, in "A Theory of Modal Dialectics', Journal of Philosophical Logic 15 (1986), 191-217.

3 Beth is probably best known as the father of the method of semantic tableaux, and also of a theorem in the theory of definition. Opus magnum: Beth (1959).

4 See L. E. J. Brouwer, Leven, kunst en mystiek (Life, Art, and Mysticism), Delft: 1905; also the articles in NCR Handelsblad by Rudy Kousbroek, October-November 1982. This book of Brouwer's has never been translated-a remarkable but understandable fact, since the book discloses an inhumanity of the most serious kind (total distegard for other people's well-being and even for their lives: combined with contempt for language and logic as means for communication).

5 Beth (1970), p. 74. Professor S. J. Doorman reminded me of this passage.

6 The quotation from Peirce in Beth's famous paper 'Semantic Entailment and Formal Derivability' (Mededelingen der Kon. Akad. van Wet., N. R., vol. 18, No. 13, Amsterdam: North Holland, 1955) seemed to one reader (who told me so) to testify to the same purely rationalist pattern of values in Beth's mind as in the minds of other logicians of his time. This is a complete misunderstanding. Given important parts of his (1959) and the collection of philosophical papers (1968), and the drift and 
direction of his organizational endeavors, what we have said about him stands unrefuted by this one quotation. We shall have to grant a thinker who is trained in mathematics an occasional reference to the delights of mental work!

7 See J. F. Staal's bibliography of Beth's works (1965)

8 John L. Pollock, Language and Thought Princeton, N.J.: Princeton U.P. 1982. The philosophy offered in this book tallies very well indeed with Beth's and Manin's.

See here also my 'Logic to some purposeTen theses against the Deductive-Nomological Paradigm in the science of logic', in: Argumentation: Across the Lines of Discipline. Proceedings of the Conference on Argumentation 1986 (eds. Frans H. van Eemeren, Rob Grootendorst a.o.), Dordrecht: Foris Publications $1987 ; 33-45$.

10 Unpublished Master's Thesis, University of Amsterdam, 1988.

11 More historical and technical details are found in another variant of this paper (to be had from the author on request).

12 Beth's sometime student J. F. Staal did research on Indian logic. J. F. Staal, 'Contraposition in Indian Logic', in: Logic, Methodology and Philosophy of Science: Proceedings of the 1960 International Congress, Stanford 1962, 634-49; also "Negation and the Law of Contradiction in Indian Thought: A Comparative Study', Bulletin of the School of Oriental and African Studies 25 (1962), 52-71. In this connection I would like to mention Joseph Wenzel's paper at the Venice conference on Wake Forest University in 1988 , which in my opinion reports on research with high relevance to what Beth meant here.

13 Translated from the Dutch by E. M. Barth; cf. Beth (1960), Beth (1970) $131 \mathrm{ff}$.
14 Lay-out by the present author

15 Except, of course, in my own department!

$16 \mathrm{Cf}$. Beth (1970), p. 78; the quotation is from the Dutch original (p. 78) as translated by me; emphases are also mine. E. M. B.

17 Some years ago the professorial chair that once was erected for Beth was taken off the payroll of the Faculty of Philosophy of the University of Amsterdam and moved to that of Mathematics. Since then the once world famous Institute for Logic and the Foundations of the Exact Sciences belongs to the past-precisely what Beth during his last illness feared might happen. It is not likely that that university will provide a chair for Logic from which his ideal of a comprehensive logic at the service of culture in general, a logic with a human face, so to speak, may be propagated.

${ }^{18}$ E. W. Beth, 'Opmerkingen over analytische wijsbegeerte" (Remarks on analytic philosophy), Algemeen Nederlands Tijdschrift voor Wijsbegeerte 53 (1961), No. 5, 1-5. The paper is a critique of the perspective and classifications of J. O. Urmson who had offered distinctions that Beth (rightly, in my opinion) judged to be historically and systematically untenable, within the confines of a provincial British outlook on what is to count as analytic philosophy, as described in his Philosophical Analysis: its development between the two world wars (Oxford, 1956).

$19 \mathrm{Cf}$. Beth's reluctance as an organizer to put logic under general philosophy or under mathernatics - see Section 5 above. It seems to me that Beth's hopes for logic do not thrive under the organizational solution that he did choose either: a separate association for Logic, Methodology, and Philosophy of Science. There is very little understanding among its members for his wish to develop a broadly culturally and politically as well as mathematically and scientifically oriented logic.

\section{Works by Evert W. Beth}

An almost complete bibliography is found in: J. F. Staal, 'E. W. Beth 1908-1964', DialecticaInternational Review of Philosophy of Knowledge 19 (1965), 160-179. A practically complete bibliography can be had from the Evert Willem Beth Foundation, P.O. Box 19121, $1000 \mathrm{GC}$
Amsterdam, The Netherlands.

The following among his books are of particular interest from a general philosophical point of view (and contain further bibliographical data):

-The Foundations of Mathematics-A Study in 
the Philosophy of Science, Amsterdam: NorthHolland Publishing Company 1959, 1965 (revised edition). Paper, Harper \& Row 1966 (Harper Torchbooks. The Science Library, TB 581 X). Parts I and IX are of a direct philosophical importance. Parts II, III, V and VI presuppose that the reader already takes a certain interest in the problems of the foundations of mathematics ("What is mathematics about?") or of logic ("Where do logical paradoxes come from?"). Parts IV, VII and VIII treat of metamathematical problems concerning the scope of formalized symbolic systems.

-. 'Considerations about Logical Thinking,' Mededelingen der Kon Akad, van Wet., N.R., vol. 23. No. 1 (1960). Reprinted in (1970).

-Science, A Road to Wisdom. Collected philosophical studies. Dordrecht (Holland): D. Reidel, 1968. (Transl. by Peter Wesly from Door wetenschap tot wijsheid. Verzamelde wijsgerige studies,
Assen (Holland): Van Gorcum \& Comp. 1964.)

-Aspects of Modern Logic, Dordrecht: D. Reidel 1970. (Transl. by D.H.J. de Jongh and S. de Jongh-Kearl from: Moderne logica, Assen: Van Gorcum \& Comp. 1967.) Written for beginners in logic and containing the best introduction to his method of "semantic tableaux".

\author{
E.M. BARTH \\ INSTITUTE FOR LOGIC, THEORETICAL \\ PHILOSOPHY AND THE HISTORY \\ OF THE EXACT SCIENCES \\ GRONINGEN UNIVERSITY \\ and
}

THE EVERT WILLEM BETH FOUNDATION p/a THE ROYAL NETHERLANDS ACADEMY OF ARTS AND SCIENCES

P.O. BOX 19121, 1000 GC AMSTERDAM

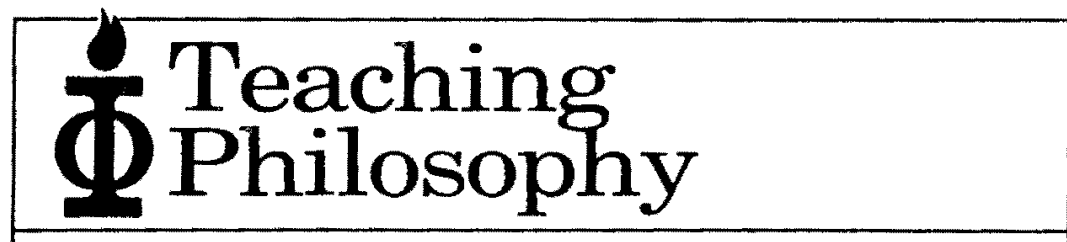

Teaching Philosophy is a quarterly journal which serves as a forum for the exchange of ideas and information about the teaching and learning of philosophy. Articles, discussions, reports and reviews are published on topics such as:

- theoretical issues in the teaching of philosophy

- innovative methods and classroom stratagems

- experimental and interdisciplinary courses

- faculty development and student counseling

1990 Subscriptions: $\$ 19.50$ individuals; $\$ 48$ institutions. Add $\$ 4$ for all subscriptions outside the U.S. Order from the PHILOSOPHY DOCUMENTATION CENTER, Bowling Green State University, Bowling Green, OH 43403-0189 USA.

Edited by: Arnold Wilson, University of Cincinnati, Cincinnati, OH 45221.0206 . 